\title{
Mussels in flow: drag and dislodgement by epizoans
}

\author{
Jon D. Witman ${ }^{1}$ and Thomas H. Suchanek ${ }^{2 *}$ \\ ${ }^{1}$ Zoology Department, University of New Hampshire, Durham, New Hampshire 03824, USA \\ ${ }^{2}$ Division of Environmental Studies, University of California, Davis, California 95616, USA
}

\begin{abstract}
Measurements of attachment strength of the mussels Mytilus californianus and Mytilus edulis were related to measurements of drag on mussels with algal epizoans in order to understand the ecological mechanics of mussel dislodgement. Attachment strength increased with shell area, and was influenced by the location of the mussel within the aggregation, and by the exposure of the habitat. $M$. californianus had a stronger attachment than $M$. edulis. In both species, significantly greater force was required to dislodge mussels at the edge of the mussel bed than at the center. The mean attachment strength of $M$. edulis was 15 times greater in exposed habitats than in protected habitats. In the lab and field, mussels overgrown by kelp encountered flow-induced forces that were 2 to 6 times greater than flow forces on the mussels alone. Flow-induced forces ranged from 0.12 to 1.08 Newtons, and increased with velocity from 12 to $62 \mathrm{~cm} \mathrm{~s}^{-1}$. There was no significant relation between surface area of attached kelp and drag. Flow force data and surveys of dislodged mussels at an exposed beach indicate that epizoans increase the risk of mussel dislodgement, which has important implications for intertidal mussel beds impacted by disturbance events.
\end{abstract}

\section{INTRODUCTION}

In many space-limited marine systems, plants and animals are often used as a substratum by other organisms (epiphytes and epizoans). Mussels are frequently overgrown by epizoans because they are sessile and present a large area of hard substratum for attachment (Suchanek, 1979). The effect of the epizoan on the underlying host organism may be positive, neutral, or negative. A common benefit of epizoism is protection from predation (Ross, 1971; Bloom, 1975; Vance, 1978). Frequently tubiculous polychaetes, bryozoans, and other colonial invertebrate epizoans do not have any appreciable effect on their hosts (Seed and $O^{\prime}$ Connor, 1981). Epizoans can affect the host adversely by smothering it (Burrows and Lodge, 1950; Dayton, 1973), by interfering with suspension feeding (Paine, 1976), by eroding the host's shell (Korringa, 1951), or by causing the host to be torn loose from the substratum (Dayton, 1973; Paine, 1979). Epizoans may influence the survival of individual organisms (Rutzler,

\footnotetext{
- Present address: 4124 Tami Way, Carmichael, California 95608, USA
}

1970) and the persistence of entire communities (Vance, 1978).

As inhabitants of exposed shores, mussels live in a mechanically stressful environment. Water velocities in the intertidal zone can reach $16 \mathrm{~m} \mathrm{~s}^{-1}$ (reinterpretation of Jones and Demetropoulos, 1968 in Vogel, 1981). Thus, the survival of mussels is to a large extent dependent on their ability to form a strong attachment in order to withstand large forces imparted by wave shock and surge. High mortality of mussels occurs during storms when they are dislodged by waves (Thiesen, 1968; Harger and Landenberger, 1971; Dayton, 1973; Paine and Levin, 1981; Witman, 1983). Factors that increase the hydrodynamic forces exerted on a mussel will be important determinants of mussel survival since they will increase the probability that the mussel will be dislodged. The hydrodynamics of mussel dislodgement are at best, poorly understood.

Here, we examine the negative consequences of epizoism for the mussels Mytilus californianus and $M$. edulis on the coast of Washington state, USA. We take a mechanical approach to the problem by relating the attachment strengths of mussels at exposed and protected sites to the hydrodynamic forces impinging on mussels with attached organisms. In lab and field 
experiments, we demonstrate for the first time that algal epizoans increase the risk of dislodgement by increasing the flow-induced forces on the mussel. We conclude by presenting several predictions about the susceptibility of mussels to disturbance events.

\section{METHODS}

\section{Attachment strength}

A direct force measuring system was used to measure the attachment strengths of intertidal Mytilus edulis and $M$. californianus at Tatoosh Island $\left(48^{\circ} 25^{\prime} \mathrm{N}\right.$, $124^{\circ} 45^{\prime} \mathrm{W}$ ) on the outer Washington coast (see Suchanek, 1979 for detailed maps). The system consisted of a calibrated force transducer, an instrumentation amplifier, and a voltage controlled oscillator constructed by $M$. Denny, and similar to that described by Denny (1982). A string mesh was attached to each mussel and the signal resulting from the force required to dislodge the mussel (i.e. by pulling at right angles to the substratum and breaking byssal attachments) was recorded on a cassette tape. The data were later printed out on a chart recorder standardized for force in Newtons.

The attachment strengths of intertidal Mytilus edulis growing on the dock at Friday Harbor Laboratory $\left(48^{\circ} 33^{\prime} \mathrm{N}, 123^{\circ} 0^{\prime} \mathrm{W}\right)$, Washington were measured following the methods of Harger (1970). Mussels were hooked onto a spring dynamometer (constructed to record maximum force) with a wire loop. Force was applied perpendicular to the mussel bed until the mussel was dislodged.

At both exposed (Tatoosh Island) and protected (Friday Harbor) sites, measurements of attachment strength were recorded for mussels occupying positions at the approximate center of the mussel bed and from mussels at the edge of the bed. To facilitate comparison to earlier studies, the size of individual mussels is expressed as a correlate of shell area (shell length $X$ width; Harger, 1970). Since the attachment strength of Mytilus edulis changes with season (Price, 1980), measurements were taken from exposed and protected sites during the same season (summer) but in different years (1975 exposed; 1981 protected). We use the terms 'attachment strength' and 'dislodgement force' interchangeably in the text.

\section{Drag experiments}

Another force transducer (constructed by J. Witman but similar to that designed by Denny, 1982) was used to measure flow-induced forces on Mytilus edulis with and without the kelps Laminaria saccharina and Alaria marginata attached to the shells (Fig. 1). When a force was applied perpendicular to the strain gauges in the transducer, the beams deflected, causing a change in electrical resistance which was measured as a voltage signal proportional to the force applied to the transducer. Both lift and drag forces could be measured by changing the orientation of the strain gauges so that they were perpendicular to the force. The transducer was calibrated four times in lift and drag modes by hanging a series of weights on it. Repeated calibrations yielded a standard error of $2.5 \%$.

Mytilus edulis overgrown by different sizes and shapes of kelp (Laminaria saccharina and Alaria marginata) were collected from the lab dock and allowed to reattach to the Plexiglas disks so that they could be fitted to the force transducer. Mussels were contained in outdoor aquaria at $11^{\circ} \mathrm{C}$ until several byssus threads were formed. Each disk was then bolted to the dock and held until needed. Mussels used in the experiments were attached by a minimum of 25 byssus threads.

The force transducer was clamped onto a ringstand and placed into the recessed area of a large flow tank (Vogel and LaBarbera, 1978) so that the Plexiglas mounting disk was flush with the floor of the flow tank (Fig. 1). Flow force measurements were taken over a velocity range of 12 to $62 \mathrm{~cm} \mathrm{~s}^{-1}$. For the lab flow regimes, Reynolds' numbers (Re)

$$
\operatorname{Re}=\frac{\mathrm{Q} \mathrm{UL}}{\mu}
$$

- where $\varrho=$ density of the fluid $\mathrm{U}=$ velocity; $\mathrm{L}=\mathrm{a}$ linear dimension of the object in flow; $\mu=$ viscosity of the fluid - ranged from $9.0 \times 10^{3}$ to $2.1 \times 10^{4}$ based on shell length of mussels, and from $5.3 \times 10^{4}$ to $2.7 \times 10^{6}$ based on length of attached kelp. One complete experimental trial consisted of the following measurements on each overgrown mussel: (1) lift force; (2) drag force; (3) attached kelp cut off the mussel and lift and drag measurements repeated on the mussel alone. Since the flow-induced force on a mussel placed the byssus threads in tension, net force was calculated as the resultant of lift and drag vectors (Fig. 1). Calculating net force as a summed vector of 2 separate measurements assumes that maximum lift and drag occur at the same time. We believe that the summed vector method is justified for the unidirectional flow conditions in which the experiments were conducted because flow force values measured directly in the field were comparable to those recorded in the flow tank.

In order to measure drag on mussels overgrown by large kelps, it was necessary to set up the force transducer in the field. The transducer was bolted onto a bar which extended out perpendicular to the end of the lab 
Fig. 1. Diagram of force transducers used to measure flow forces on mussels with attached kelp. (A) Side view of force transducer in Plexiglas housing oriented to measure lift forces. (B) Side view of same transducer, but with orientation changed to measure drag forces. Open arrow: flow direction in (A) and (B). Bottom inset: direction of forces with net force calculated as resultant of lift and drag vectors. $M D$ mounting disk; H housing; $\mathrm{SG}$ strain gauge attached to thin Plexiglas beam; AR arm constructed from brass shim stock; MA milled area; C shielded cable. Transducers are wired to an instrumentation amplifier and an ohmmeter. Stippled area: Plexiglas material. Kelp not drawn to scale

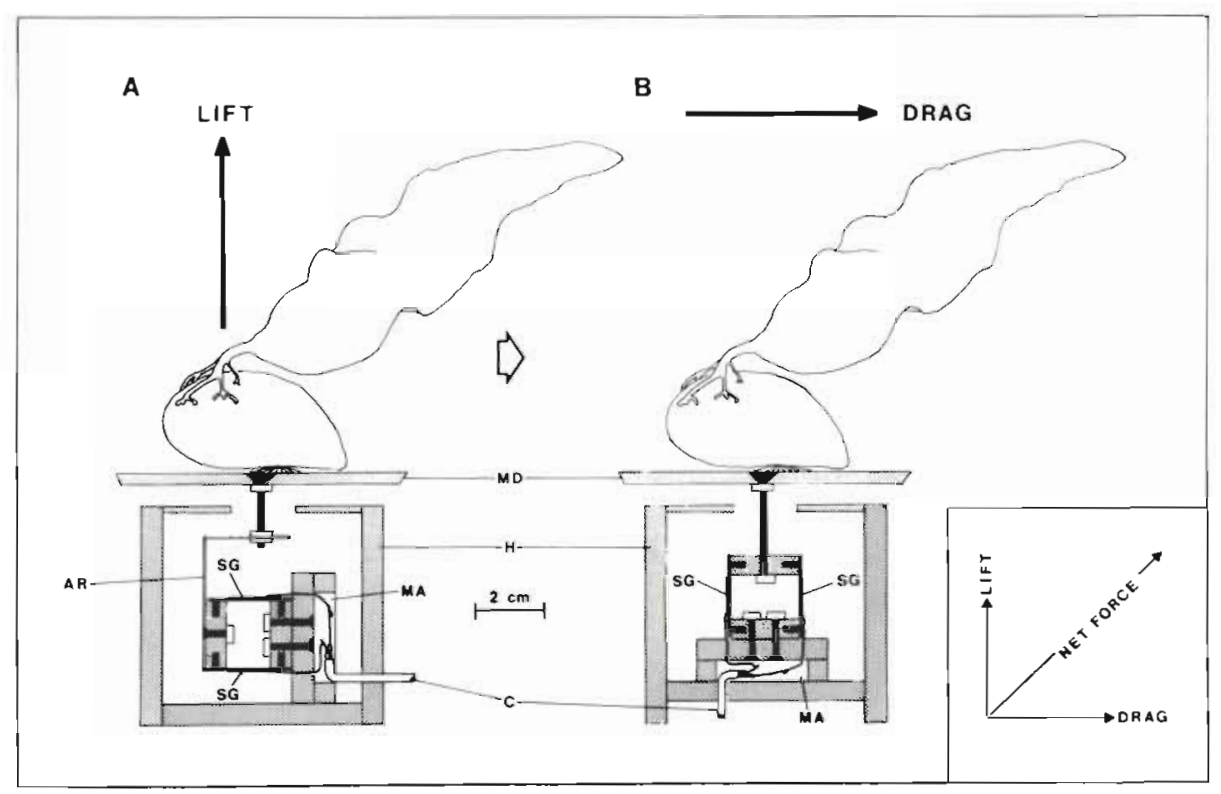

dock. Overgrown mussels were tied to the transducer with a $3 \mathrm{~m}$ long nylon line, and were exposed to a unidirectional tidal current flowing parallel to the dock. Since the overgrown mussel was on the end of a line, it was free to move with respect to flow and oriented parallel to the drag forces exerted on it. This enabled drag to be measured without changing the orientation of the transducer. As in the lab, the effect of the kelp on force was determined by the difference between drag on the mussel with attached kelp and drag on the mussel alone. Flow velocities were measured with a thermistor flow probe (LaBarbera and Vogel, 1976). Reynolds' numbers ranged from $9.0 \times 10^{3}$ to $1.0 \times 10^{4}$ based on shell length of mussels, and from $1.3 \times 10^{6}$ to $3.9 \times 10^{6}$ based on length of attached kelp.

\section{Observations of dislodged mussels}

On 32 occasions between 1973 and 1978, a portion of Shi Shi Beach $\left(48^{\circ} 15^{\prime} \mathrm{N}, 124^{\circ} 40^{\prime} \mathrm{W}\right.$; on the outer coast of Washington) was surveyed for dislodged Mytilus californianus. The number of mussels cast ashore were recorded, and any epizoans on the dislodged mussels were identified.

\section{Statistical analyses}

One way analysis of variance was performed on $\log (x+1)$ transformed data to compare attachment strengths of mussels. Regression analysis (least squares) was conducted to relate mussel size to attach- ment strength, and net force to velocity. The slopes of mussel size versus attachment strength regressions were compared for different positions within the mussel bed by a Student's t test (Sokal and Rohlf, 1969).

\section{RESULTS}

\section{Dislodgement forces}

Fig. 2 shows the forces required to remove Mytilus californianus and $M$. edulis from the substratum in relation to shell area. There was a significant linear relation between dislodgement force and shell area for $M$. californianus from the edge of the mussel bed $\left(\mathrm{r}^{2}=\right.$ $0.85, \mathrm{p}<0.01$ ). Too few measurements were taken from $M$. californianus at the center of the mussel bed to permit regression analysis $(n=5)$; however, all of the data points from the center lie substantially below the regression line from the edge. Thus, less force is required to dislodge $M$. californianus from the center of the mussel bed than from the edge. As with $M$. californianus, dislodgement force increased with shell area for Mytilus edulis (edge mussels: $r^{2}=0.71$, $p<0.001$; center mussels: $\left.r^{2}=.87, p<0.001\right)$. A comparison of the slopes of regression lines between edge and center Mytilus edulis revealed that they are significantly different $\left(t=2.68 ; 1,29 \mathrm{df}_{\mathrm{i}} \mathrm{p}<0.02\right)$ indicating that less force is required to dislodge mussels located at the center of a $M$. edulis bed.

The mean dislodgement forces of the 2 species of Mytilus from different habitats and positions within the mussel bed are presented in Table 1. Highest disladgement forces occurred in $M$. californianus from the 
mussel bed edge, followed by $M$. californianus from the center of the mussel bed. At the exposed site, significantly greater force was required to dislodge $M$. californianus than $M$. edulis (positions pooled within beds: $F=7.04,1,27 \mathrm{df}, \mathrm{p}<0.025$ ). $M$. californianus was too rare at the protected site to allow a comparison

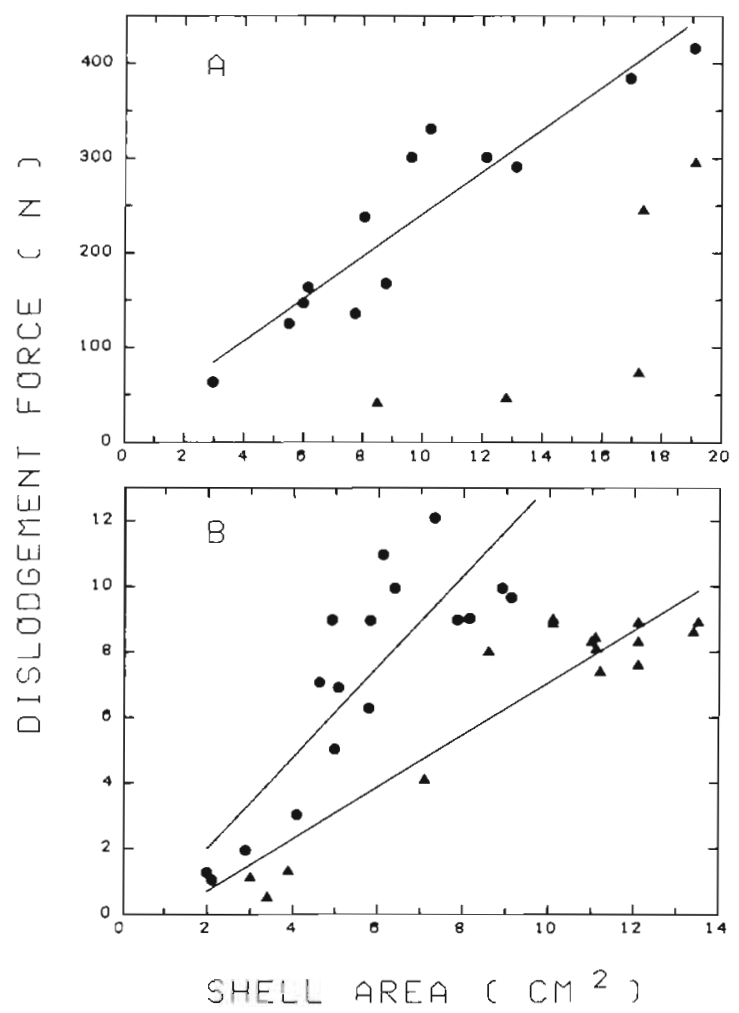

Fig. 2. Dislodgement force (in Newtons) of Mytilus californianus $(\mathrm{A})$ and $M$. edulis $(\mathrm{B})$ in relation to a correlate of shell area (shell length $\times$ width). Circles: measurements from edge of mussel bed ${ }_{i}$ triangles: measurements from center of mussel bed. Regression lines calculated by least squares method (Sokal and Rohlf, 1969)

between species. A comparison of the mean dislodgement force of $M$. edulis between exposed and protected sites indicated that the attachment strength of mussels living in exposed habitats is significantly greater than those in protected habitats (positions pooled within beds: $\mathrm{F}=135 ; 1,43 \mathrm{df}, \mathrm{p}<0.001$ ).

\section{Drag from attached kelp}

Measurements of flow force in the lab flow tank and in the field showed that moving water subjects mussels with attached kelp to drag forces that are greater than the drag forces on the mussels alone (Fig. 3 and 4). Drag on mussels fouled by kelp ranged from 0.25 to 1.08 Newtons, representing a 2 to 6.7 fold increase of

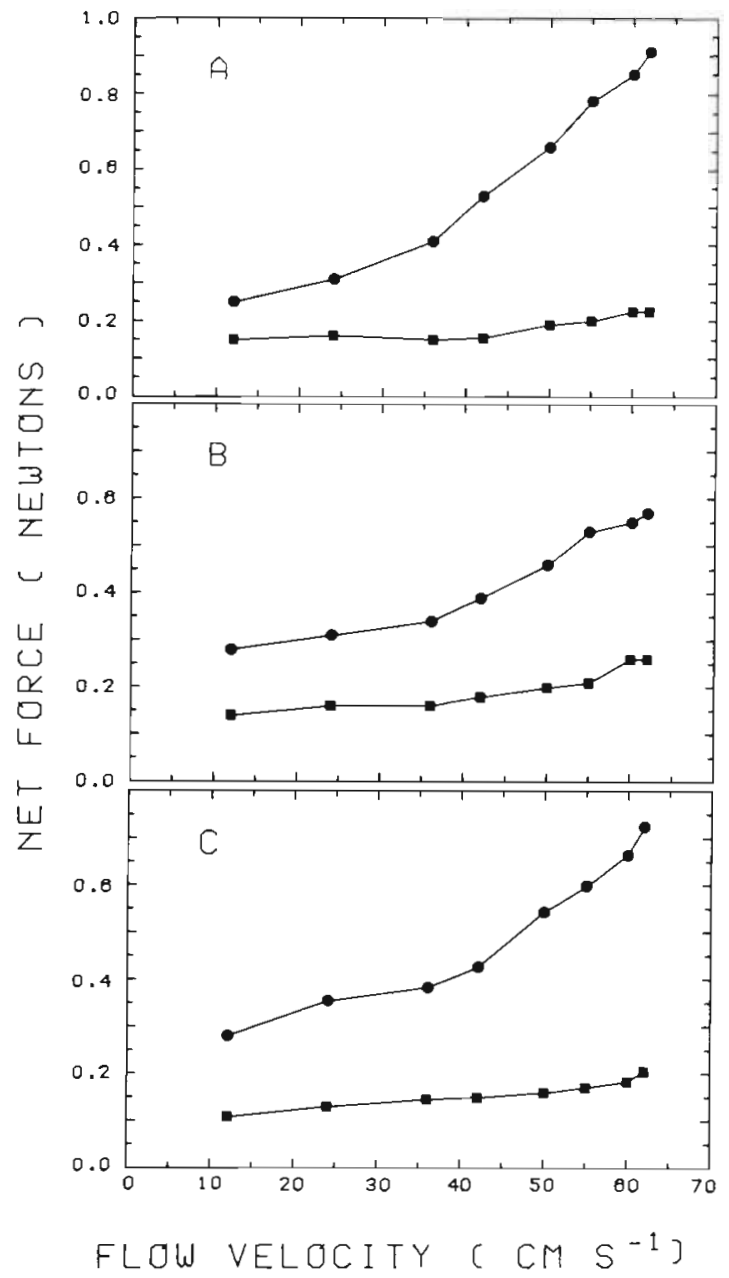

Fig. 3. Drag forces on Mytilus edulis with attached kelp (circles) and on the same mussels alone (squares) from the flow tank experiments. Surface area of the Laminaria saccharina attached to each individual mussel was $204 \mathrm{~cm}^{2}$ in (A), $400 \mathrm{~cm}^{2}$ in (B), and $190 \mathrm{~cm}^{2}$ in (C). Overgrown mussels reoriented in $(\mathrm{B})$ and $(\mathrm{C})$

tensile stress on the byssus attachment. In the flow tank experiments, net force on mussels overgrown by kelp was positively correlated with flow velocity over a velocity range of 12 to $62 \mathrm{~cm} \mathrm{~s}^{-1}$ (Table 2).

Mussels and attached algae responded to increased flow differently. Fig. 5 shows how force on the attached kelp changed the orientation of the mussel. In 2 of the 3 trials in the flow tank, the posterior end of the mussel was elevated at $36 \mathrm{~cm} \mathrm{~s}^{-1}$. As flow was subsequently increased to $62 \mathrm{~cm} \mathrm{~s}^{-1}$, the mussels were twisted around to a final orientation $70^{\circ}$ and $80^{\circ}$ from the original orientation (long axis of mussel parallel to flow). This effect increased the projected area of the shell normal to flow by $278 \%$ for the $70^{\circ}$ orientation and $297 \%$ for the $80^{\circ}$ orientation, no doubt increasing drag. Three Laminaria saccharina plants attached to the mussels responded to increased flow by bending over toward the substratum. Stipe angles decreased 
Table 1. Mytilus californianus and $M$. edulis. Mean dislodgement forces from different habitats and locations in mussel beds. Exposed habitat is Tatoosh Island; protected habitat is Friday Harbor. Data expressed as mean value \pm standard error $\mathrm{N}=$ sample size. Dislodgement force in Newtons

\begin{tabular}{lllrr|}
\hline Species & Habitat & $\begin{array}{l}\text { Location in } \\
\text { mussel bed }\end{array}$ & $\mathrm{N}$ & Dislodgement force \\
\hline M. californianus & Exposed & Edge & 12 & $241.8 \pm(32.6)$ \\
M. californianus & Exposed & Center & 5 & $140.0 \pm(53.7)$ \\
M. edulis & Exposed & All locations & 10 & $103.8 \pm(20.7)$ \\
$M$. edulis & Protected & Edge & 17 & $7.1 \pm(0.86)$ \\
M. edulis & Protected & Center & 16 & $6.1 \pm(0.74)$ \\
\hline
\end{tabular}

from an orientation perpendicular to the floor of the flow tank $\left(90^{\circ}\right)$ at zero velocity to $74^{\circ}, 80^{\circ}$ and $76^{\circ}$ as the stipes deflected in the downstream direction. All of the kelp blades began to flutter at $36 \mathrm{~cm} \mathrm{~s}^{-1}$ i fluttering was most violent in the kelp with an elongate blade (net force graphed in Fig. 3a).

There was a poor correlation between the surface area of attached kelp and drag $(r=0.59, p>.05)$ as indicated by the field measurements. Consequently, the surface area of the attached kelp is a poor predictor of drag. This is further substantiated by a comparison

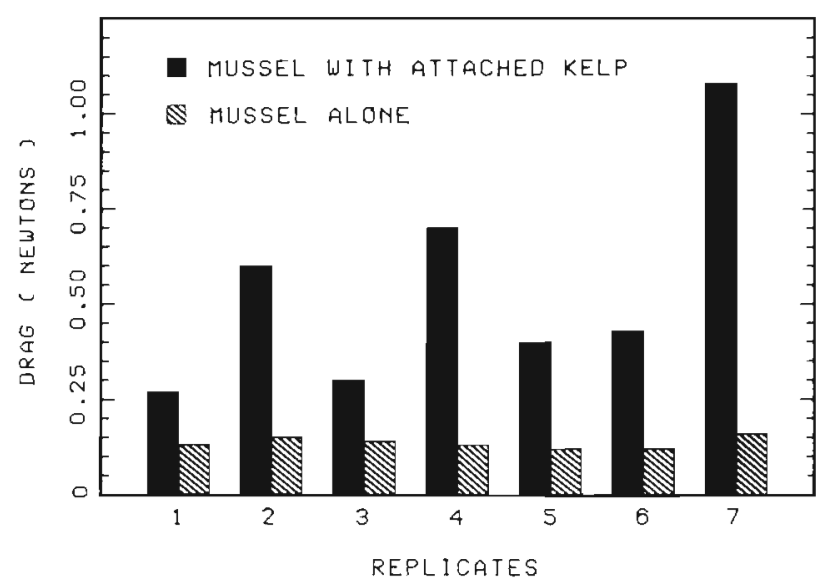

Fig. 4. Bar graph of drag on mussels with and without attached kelp from field measurements taken at a flow velocity of $30 \mathrm{~cm} \mathrm{~s}^{-1}$. Replicates 1 to 7 arranged in order of increasing surface area of attached kelp: (1) Laminaria saccharina, $756 \mathrm{~cm}^{2}$ surface area; (2) L. saccharina, $1104 \mathrm{~cm}^{2}$; (3) Alaria marginata, $1350 \mathrm{~cm}^{2}$; (4) L. saccharina, $1500 \mathrm{~cm}^{2}$; (5) A. marginata, $1620 \mathrm{~cm}^{2}$; (6) L. saccharina, $2740 \mathrm{~cm}^{2}$; (7) L. saccharina, $2880 \mathrm{~cm}^{2}$

of drag values in the lab and field at a velocity of $30 \mathrm{~cm} \mathrm{~s}^{-1}$. In the field measurements, the kelp attached to mussels had a surface area that was 2 to 10 times greater than the kelp used in the lab, yet the drag was not significantly different from the drag recorded in the lab $(F=1.25 ; 1,8 \mathrm{df}, \mathrm{p}>.05)$. Similarly, values of drag on mussels alone at $30 \mathrm{~cm} \mathrm{~s}^{-1}$ did not differ significantly between lab and field trials $(F=.97 ; 1$, $8 \mathrm{df}, \mathrm{p}>.05)$.

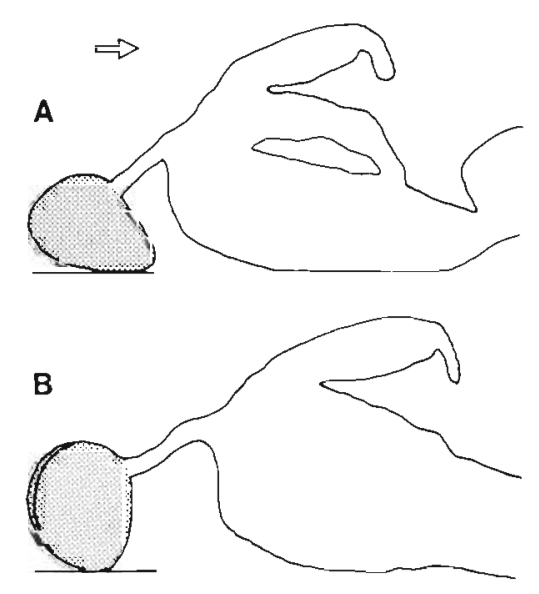

Fig. 5. Drawing (from photographs) of a mussel with attached kelp at a flow velocity of $12 \mathrm{~cm} \mathrm{~s}^{-1}$ (A), and at $60 \mathrm{~cm} \mathrm{~s}^{-1}$ (B). showing how kelp-induced drag rotated the mussel until it ended up $70^{\circ}$ from the original orientation (A). A greater area of shell was broadside to water flow in (B). Arrow: direction of water flow; mussel shell stippled

\section{Dislodgement as a consequence of epizoism}

Table 2 relates the force required to dislodge Mytilus edulis in the protected habitat to net force from attached kelp. From the regression equations of velocity on net force, it was possible to predict the velocity required to produce the minimum dislodgement force (1.0 $\mathrm{N}$ for $M$. edulis with $2.0 \mathrm{~cm}^{2}$ shell area). It is clear that a mussel overgrown by kelp can be dislodged at substantially lower flow velocities than a non-overgrown mussel. Therefore, overgrown mussels will have a greater risk of dislodgement.

Observations on the occurrence of epizoans on Mytilus californianus from Tatoosh Island and Shi Shi Beach indicate that a large number of algal and sessile invertebrate taxa colonize mussel shells (Table 3). However, only a few taxa tend to decrease the survival of the mussels. Data collected on the number of $M$. californianus dislodged during winter storms and cast ashore at an exposed habitat (Shi Shi Beach) show that 
Table 2. Regression equations of flow velocity on net force from flow tank experiments and predicted flow velocities to produce the minimum dislodgement force for Mytilus edulis (1.0 Newton). $y=$ net force in Newtons; $\mathrm{x}=\mathrm{flow}$ velocity in $\mathrm{cm} \mathrm{s}^{-1}$; $\mathrm{r}^{2}=$ coefficient of determination; surface area of kelp in $\mathrm{cm}^{2}$, predicted velocities in crn $\mathrm{s}^{-1}$. Equations are best fit to a power curve or a linear regression by the least squares method

\begin{tabular}{|c|c|c|c|c|}
\hline & Net force measurement & \multicolumn{2}{|c|}{ Regression equation } & Predicted velocity $\left(\mathrm{cm} \mathrm{s}^{-1}\right)$ \\
\hline \multirow[t]{2}{*}{ (1) } & $\begin{array}{l}\text { Mussel with attached } \\
\text { L. saccharina }\left(204 \mathrm{~cm}^{2}\right)\end{array}$ & $y=.03 x^{82}$ & $\mathrm{r}^{2}=.91$ & 81 \\
\hline & Mussel only & $y=.11+.00157 x$ & $\mathrm{r}^{2}=.74$ & 566 \\
\hline \multirow[t]{2}{*}{ (2) } & $\begin{array}{l}\text { Mussel with attached } \\
\text { L. saccharina }\left(400 \mathrm{~cm}^{2}\right)\end{array}$ & $y=.08 x^{.45}$ & $\mathrm{r}^{2}=.84$ & 271 \\
\hline & Mussel only & $y=.1+.00234 x$ & $r^{2}=.85$ & 384 \\
\hline \multirow[t]{2}{*}{ (3) } & $\begin{array}{l}\text { Mussel with attached } \\
\text { L. saccharina }\left(190 \mathrm{~cm}^{2}\right)\end{array}$ & $y=.06 x^{55}$ & $\mathrm{r}^{2}=.87$ & 147 \\
\hline & Mussel only & $y=.09+.00165 x$ & $\mathrm{r}^{2}=.93$ & 555 \\
\hline
\end{tabular}

Table 3. Mytilus californianus. Number of epizoic taxa occurring on shells at Tatoosh Island and Shi Shi Beach. See Suchanek (1979) for complete species list

\begin{tabular}{|c|c|}
\hline Taxon & Number of species \\
\hline \multicolumn{2}{|l|}{ ALGAE } \\
\hline Chlorophyta & $3+$ \\
\hline Phaeophyta & $7+$ \\
\hline Rhodophyta & $15+$ \\
\hline \multicolumn{2}{|l|}{ INVERTEBRATES } \\
\hline Porifera & 3 \\
\hline \multicolumn{2}{|l|}{ Cnidaria } \\
\hline Hydrozoa & 9 \\
\hline Anthozoa & 3 \\
\hline \multicolumn{2}{|l|}{ Mollusca } \\
\hline Bivalvia & 2 \\
\hline \multicolumn{2}{|l|}{ Annelida } \\
\hline Polychaeta & 11 \\
\hline \multicolumn{2}{|l|}{ Arthropoda } \\
\hline Crustacea (Ciripedia) & 6 \\
\hline \multicolumn{2}{|l|}{ Bryozoa } \\
\hline Gymnolaemata & 17 \\
\hline \multicolumn{2}{|l|}{ Chordata } \\
\hline Urochordata (Ascidiacea) & 1 \\
\hline
\end{tabular}

a greater number of mussels with epizoans were dislodged than those without epizoans (Table 4). The greatest number of mussels were dislodged as a correlate of overgrowth by the brown alga Fucus distichus, followed by the barnacles Semibalanus cariosus and Balanus nubilus.

\section{DISCUSSION}

\section{Structural integrity of mussel beds}

The probability that a mussel will be dislodged is determined by factors operating on the following 3
Table 4. Mytilus californianus. Number of dislodged individuals with and without ${ }^{*}$ epizoans cast ashore on Shi Shi Beach. Data pooled, observations conducted from 1973-1978

\begin{tabular}{|lcc|}
\hline Epizoan & $\begin{array}{c}\text { Mussels with } \\
\text { epizoans }\end{array}$ & $\begin{array}{c}\text { Mussels } \\
\text { attached to } \\
\text { fouled mussels }\end{array}$ \\
\hline AlGAE & 88 & 7 \\
Fucus distichus & 14 & 43 \\
Laminaria spp. & 27 & 2 \\
Postelsia palmaeformis & & 30 \\
BARNACLES & 61 & 4 \\
Semibalanus cariosus & 36 & \\
Balanus nubilus & & \\
- We recorded 85 dislodged mussels without epizoans \\
\hline
\end{tabular}

levels of mussel bed organization: (1) byssus attachment; (2) individual mussel; (3) mussel bed structure.

A variety of environmental factors influence the strength of the byssus attachment, which is a function of the number of byssus threads anchoring the mussel (Allen et al., 1976; Smeathers and Vincent, 1979). Strong attachment is achieved by secreting a large number of threads. Within the thermal tolerance range of the species, the rate of byssus thread formation was positively correlated with temperature for Mytilus edulis (Glaus, 1968; Allen et al., 1976) and for Geukensia demissa (Van Winkle, 1970). Glaus (1968) showed that $M$. edulis produced the greatest number of byssus threads at a salinity of 33 ppt which was intermediate between experimental salinities of 15.9 and $46.3 \mathrm{ppt}$. Low salinities reduced the rate of thread formation by $M$. edulis and $G$. demissa (Van Winkle, 1970). Other factors known to inhibit byssus thread formation by $M$. edulis include low oxygen concentration (Reish and Ayers, 1968), high concentration of chloride ions (Reish 
and Ayers, 1968), and high dinoflagellate concentrations during outbreaks of red tide (Van Winkle, 1970). Smeathers and Vincent (1979) showed that the tensile stress of wet byssus thread $(.25 \mathrm{~N})$ is doubled when it is dry,

Our results indicate that the force required to remove individual Mytilus californianus and $M$. edulis was size dependent. Dislodgement force increased as a function of shell area. This is consistent with the results of Harger (1970) for $M$. californianus but not for $M$. edulis. Harger (1970) found that attachment strength of $M$. edulis increased with shell area up to $10 \mathrm{~cm}^{2}$, but leveled off beyond this size.

More force was required to dislodge Mytilus californianus than $M$. edulis, which is in accord with Harger (1970). However, dislodgement force values recorded for both Mytilus species at Tatoosh Island were substantially higher than those recorded by Harger (1970) from pilings at Ellwood Pier, in Santa Barbara, California (USA). For example, we recorded a range of 41 to 416 Newtons for different sizes of $M$. califomianus at Tatoosh which is nearly two-fold greater than the $<9$ to 245 Newton range recorded by Harger (1970). Our data represent the highest attachment strength recorded for any mussel. It took 22 to 260 Newtons of force to detach $M$. edulis at Tatoosh Island compared to 5 to 113 Newtons at Ellwood Pier. It is difficult to explain the magnitude of these differences. We suggest that they are related to the exposure of the habitat. A qualitative evaluation of the degree of exposure between the two sites suggests that Tatoosh Island is more exposed than Ellwood Pier. Tatoosh is extremely exposed to oceanic swells (Dayton, 1971; Paine and Levin, 1981) while it might be expected that the presence of adjacent pilings would dissipate some of the wave shock at Ellwood Pier. Consequently, the strong attachment of mussels at Tatoosh might reflect a response to exposure. Mussels that normally experience large forces from wave shock and surge might be able to decrease the risk of dislodgement by producing stronger or a greater number of byssus threads. Our data show that it takes significantly greater force to dislodge $M$. edulis from an exposed habitat than from a protected habitat, which supports the above interpretation. Surprisingly little is known about the influence of water movement on the rate of byssus thread formation and the corresponding attachment strength. Van Winkle (1970) demonstrated that mechanical agitation decreased the rate of byssus thread formation in Guekensia demissa. The ecological significance of this experiment is difficult to interpret because $G$. demissa is an infaunal, estuarine, mussel and is not normally subjected to high levels of agitation. Paine and Levin (1981) suggest that agitation by waves could increase the rate of byssus thread formation by $M$. californianus. Clearly, this topic deserves further attention.

Less force was required to dislodge Mytilus californianus and $M$. edulis located at the approximate center of the aggregation than at the edge. To our knowledge, this is the first demonstration that attachment strength is influenced by the location of the mussel within the bed. This result was contrary to our expectation of the structural integrity of mussel beds. Byssal attachment from adjacent mussels reinforces the attachment of mussels in the center of the aggregation (Bayne, 1976), implying that central mussels should be more strongly attached than mussels at the edge. One explanation of our result is related to the tendency of $M$. californianus and $M$. edulis to hummock in the center of the beds. Central areas of the mussel beds are often multi-layered while mussels at the periphery are mono-layered (Dayton, 1971; own obs.). Thus, fewer mussels are attached to the primary substratum in the center than at the edge. Our data indicate that mussels attached to conspecifics in the center are more easily dislodged than those attached directly to the substratum at the edge. Another possible explanation is that mussels at the edge may encounter greater flow forces imparted by breaking waves than mussels in the center. Mussels in the center of the aggregation may 'hide' from high flow forces by being behind their neighbors. Thus, edge mussels may form a stronger attachment than central mussels by laying down more byssus threads in response to greater hydrodynamic stimuli.

\section{Flow forces}

In unidirectional flow conditions in the lab and field, mussels with attached kelp encountered flow forces that were 2 to 6 times greater than forces on the mussel alone. In the same flow regime, mussels fouled by kelp will have a greater risk of dislodgement than mussels without kelp. This is the first demonstration that flowforce amplification is one of the hydrodynamic processes operating on overgrown mussels to cause dislodgement. We suggest that the effect of the attached kelp is to make the mussel 'taller', extending it out of the slow flow within a mussel bed into mainstream flow velocities.

Our results suggest that drag forces on a mussel with attached kelp may be increased by a process other than extending the mussel into mainstream flow. In this second process, the orientation of 2 mussels was changed by kelp-induced drag so that the projected area of the shell perpendicular to flow was increased dramatically (Fig. 5). Since drag is a function of projected area (Shapiro, 1961), this effect must have increased drag, although the design of our experiment 
did not allow the orientation effect to be separated from the effect of kelp on drag. However, this does not detract from the argument that drag from attached kelp is the primary mechanism of mussel dislodgement because a majority of overgrown mussels (1 in Fig. 3A, all 7 in Fig. 4) did not reorient, indicating that the increased drag was entirely due to attached kelp. In addition to increasing the flow-induced forces on the mussel, the attached kelp increases the risk of dislodgement simply because it increases the size of the structure that the byssus has to anchor to the substratum.

Drag from attached kelp was not related to the surface area of the kelp. In the flow tank experiments, the kelp with an elongate blade and the lowest surface area produced a greater drag than the kelp with a broad blade and the largest surface area. This result may be related to the violent fluttering of the smaller kelp as velocity increased. Fluttering comes from the separation of flow along the surface of an object, and creates high pressure drag (Vogel, 1981). Since elongate blades will flutter more than short ones, it is possible for a narrow kelp blade to incur more drag than a short blade with a greater surface area.

Values of flow force on mussels plus their attached kelp increased with velocity over a range of 12 to $62 \mathrm{~cm} \mathrm{~s}^{-1}$. In contrast, Charters et al. (1969) stated that drag on Eisenia arborea decreases with increasing velocity, apparently due to a decrease in the diameter of the frond clump as the digitate fronds collapsed at high velocities. These differences may be related to morphological differences of the kelps used in the 2 studies. Our flow tank experiments were conducted with Laminaria saccharina, which does not have a highly branched frond. Thus, it was prevented from using the drag reducing mechanism of Eisenia (frond collapse) by morphological constraints. The digitation of kelp blades represents an adaptation to rapid water flow seen in other species (Koehl, 1982; Norton et al., 1982).

Regression analysis of the data on net force from attached kelp supported values of $.82, .45$, and .55 for the exponents $\left(b\right.$ in net force $=a \cdot x^{b}$ ) in the equations relating net force to velocity. These exponents are lower than predicted by theory for a flat plate parallel to flow at high Reynolds numbers $(b=1.5$; Hoener, 1965). However, we conclude that these exponents are real and reflect the dynamic behavior of the kelp in flow.

Generally, drag on the mussels alone increased 2fold, as velocity increased 5 -fold. This was a surprising result, as drag should have increased as the square of velocity for a bluff body (Shapiro, 1961). The low drag on the mussel shells may reflect streamlining as the orientation of the mussel was such that streamlining could have occurred. Measurements were taken with the long axis of the mussel parallel to flow and the blunt posterior end facing the current, which is consist ent with the orientation of an object that reduces drag by streamlining (Koehl, 1977; Vogel, 1981).

\section{Implications for disturbance events}

Most of the past research on mussel dislodgement has focused on disturbance events occurring at the level of the mussel bed structure (Dayton, 1971, 1973; Harger and Landenberger, 1971; Levin and Paine, 1974; Paine and Levin, 1981). Harger and Landenberger (1971) demonstrated that the magnitude of storm dislodgement of Mytilus californianus and $M$. edulis was dependent on the size of the mussel bed and the extent of prior sea star predation. Dislodgement was greatest in large, dense, mussel beds where fewer mussels were attached directly to rock than in smaller beds. Predation by Pisaster ochraceous and $P$. giganteus on mussels at the base of the beds undercut the mussel aggregations making them more vulnerable to storms. In addition, a high proportion of $M$. edulis in an aggregation of $M$. californianus increased the instability of the bed since the attachment of $M$. edulis is weaker (Harger and Landenberger, 1971). $M$. californianus is dislodged by $\log$ battering, wave shock, and overgrowth by the brown alga Postelsia palmaeformis (Dayton, 1971, 1973; Paine, 1979), often allowing recruitment and survival of its competitively inferior congener $M$. edulis in the dominant $M$. californianus zone (Suchanek, 1978, 1981). By tagging Postelsia attached to $M$. californianus, Dayton (1973) showed that plants $10 \mathrm{~cm}$ in length incurred sufficient resistance to flow to dislodge the underlying mussel. Paine and Levin (1981) suggest that dislodgement of $M$. californianus and the subsequent creation of a patch may be caused by predation, old age, crowding, high sedimentation, and log damage.

Our results enable several predictions to be made about the susceptibility of mussel beds to large and small scale disturbance events. These predictions are eminently falsifiable, as they may be tested by controlled field experiments.

(1) Disturbance events that impact the center of Mytilus beds should cause greater destruction than events impacting the edge of the mussel beds since mussels are not as strongly attached in the center.

(2) Other factors being equal, a patch created in the center of a mussel bed should enlarge at a greater rate than patches opened at the edge, by the same reasoning as (1).

(3) Mussel epizoans that increase the height of the mussel (kelp, barnacles, lobate colonial invertebrates) 
above their neighbors and make the mussel encounter faster flow velocities will lead to drag amplification and a higher risk of dislodgement. Epizoans that form thin encrustations and do not substantially increase the vertical relief of the mussel (sheet-like sponges, tunicates, and bryozoans, non-erect crustose coralline algae) should not increase the risk of dislodgement.

(4) Some epizoans change the way the mussel encounters flow by twisting the mussel so that the shell is broadside to flow. This effect should be an important mechanism for the dislodgement of solitary mussels, but not for aggregated mussels as twisting is constrained in a tightly packed mussel bed.

(5) Finally, Mytilus edulis and M. californianus that occupy central positions within the mussel bed and are fouled by epizoans will have the greatest risk of dislodgement.

Acknowledgements. The hydrodynamics research was conducted by JDW during the Biomechanics course at Friday Harbor Marine Laboratories. Special thanks to the course instructors S. Vogel and M. LaBarbera, and to R. Emlet for advice and assistance in the lab. We thank M. Denny for the use of his force transducer at Tatoosh Island, and M. Koehl for her critique of the manuscript. The manuscript was also improved by comments from M. Hardwick-Witman, L. Harris, and J. Pearse. This study was supported by the Lerner-Gray Fund for Marine Research and a George Moore Scholarship to JDW, and by a NSF Pre-Doctoral Fellowship OCE-75-20958 and NIH/University of Washington Graduate Research Award 5-S07-RR0796-12 to THS.

\section{LITERATURE CITED}

Allen, J. A., Cook, M., Jackson, D. J., Preston, S., Worth, E. M. (1976). Observations on the rate of production and mechanical properties of the byssus threads of Mytilus edulis L. J. moll. Stud. 42: 279-289

Bayne, B. L. (1976). Marine mussels: their ecology and physiology. Cambridge University Press, Cambridge

Bloom, S. A. (1975). The motile escape response of a sessile prey: a sponge-scallop mutualism. J. exp. mar. Biol. Ecol. 17: $311-321$

Burrows, E. M., Lodge, S. M. (1950). A note on the interrelationships of Patella, Balanus, and Fucus on a semiexposed coast. Ann. Rep. for 1949, Mar. Biol. Sta. Port Erin 62: $30-34$

Charters, A. C., Neushul, M., Barilotti, C. (1969). The functional morphology of Eisenia arborea. Proc. Int. Seaweed Symp. 6: 89-105

Dayton, P. K. (1971). Competition, disturbance, and community organization: the provision and subsequent utilization of space is a rocky intertidal community. Ecol. Monogr. 41 (4) : $351-389$

Dayton, P. K. (1973). Dispersion, dispersal, and persistence of the annual intertidal alga, Postelsia palmaeformis $\mathrm{Ru}-$ precht. Ecology 54 (2): 433-438

Denny, M. W. (1982). Forces on intertidal organisms due to breaking ocean waves: design and application of a telemetry system. Limnol. Oceanogr. 27 (1): 178-183

Glaus, K. J. (1968). Factors influencing the production of byssus threads in Mytilus edulis. Biol. Bull. mar. biol. Lab., Woods Hole 135: 420

Harger, J R. E. (1970). The effect of wave impact on some aspects of the biology of mussels. Veliger 12: 401-414

Harger, J. R. E., Landenberger, D. E. (1971). The effects of storms as a density dependent mortality factor on populations of sea mussels. Veliger 14: 195-201

Hoener, S. F. (1965). Fluid-dynamic drag. (Published by author.) Midland Park, New York

Jones, E., Demetropoulos, A. (1968). Exposure to wave action: measurement of an important ecological parameter on rocky shores in Anglesey. J. exp. mar. Biol. Ecol. 2: 46-63

Koehl, M. A. R. (1977). Effects of sea anemones on the flow forces they encounter. J. exp. Biol. 69: 87-105

Koehl, M. A. R. (1982). The interaction of moving water and sessile organisms. Sci. Am. 247: 124-134

Korringa, P. (1951). The shell of Ostrea edulis as a habitat. Neth. J. Zool. 10: 32-152

LaBarbera, M., Vogel, S. (1976). An inexpensive thermistor flowmeter for aquatic biology. Limnol. Oceanogr. 21: $750-756$

Levin, S. A., Paine, R. T. (1974). Disturbance, patch formation, and community structure. Proc. natn. Acad. Sci. USA 71 (7): $2744-2747$

Norton, T. A., Mathieson, A. C., Neushul, M. (1982). A review of some aspects of form and function in seaweeds. Botanica mar. 25: 501-510

Paine, R. T. (1976). Biological observations on a subtidal Mytilus californianus bed. Veliger 19 (2): 125-129

Paine, R. T. (1979). Disaster, catastrophe, and the local persistence of the sea palm, Postelsia palmaeformis. Science, N. Y. 205; 685-687

Paine, R. T., Levin, S. A. (1981). Intertidal landscapes: disturbance and the dynamics of pattern. Ecol. Monogr. 51 (2): $145-178$

Price, H. A. (1980). Seasonal variation in the strength of byssal attachment of the common mussel Mytilus edulis L. J. mar biol. Ass. U. K. 60: 1035-1037

Ross, D. M. (1971). Protection of the hermit crabs (Dardamus spp.) from octopus by the commensal sea anemone (Calliactis spp.). Nature, Lond. 230: 401-402

Rutzler, K. (1970). Spatial competition among Porifera: solution by epizoism. Oecologia (Berl.) 5: 85-95

Reish, D. J., Ayers, J. L. (1968). Studies on the Mytilus edulis community in Alamitos Bay, California. III. The effects of reduced dissolved oxygen and chlorinity concentrations on survival and byssus thread formation. Veliger 10 : 384-388

Seed, R., O'Connor, R. J. (1981). Community organization in marine algal epifaunas. Ann. Rev. Ecol. Syst. 12: 49-74

Shapiro, A. H. (1961). Shape and flow: the fluid dynamics of drag. Heinemann, London

Smeathers, J. E., Vincent, J. F. V. (1979). Mechanical properties of mussel byssus threads. J. moll. Stud. 45: 219-230

Sokal, R. R., Rohlf, F. J. (1969). Biometry. Freeman, San Francisco

Suchanek, T. H. (1978). The ecology of Mytilus edulis L. in exposed rocky intertidal communities. J. exp. mar. Biol. Ecol. 31: 105-120

Suchanek, T. H. (1979). The Mytilus californianus community: studies on the composition, structure, organization, and dynamics of a mussel bed. Ph. D. Dissertation, Dept. of Zoology, University of Washington, Seattle

Suchanek, T. H. (1981). The role of disturbance in the evolution of life history strategies in the intertidal mussels Mytilus edulis and Mytilus californianus. Oecologia 50: $143-152$ 
Thiesen, B. F. (1968). Growth and mortality of culture mussels in the Danish Wadden Sea. Meddr Kornmn Danm. Fisk.og Havunders. 6: 47-78

Van Winkle, W. (1970). Effect of environmental factors on byssal thread formation. Mar. Biol. 7: 143-148

Vance, R. R. (1978). A mutualistic interaction between a sessile marine clam and its epibionts. Ecology 59 (4): $679-685$
Vogel, S., LaBarbera, M. (1978). Simple flow tanks for research and teaching. Bioscience 28: 638-643

Vogel, S. (1981). Life in moving fluids. Willard Grant Press, Boston

Witman, J. D. (1983). The importance of competition, physical disturbance, and mutualism in maintaining the depth zonation of kelp and mussels. (Abstr.) Am. Zool. 23: 1001

This paper was presented by Professor J. S. Pearse; it was accepted for printing on January 6, 1984 